\title{
Up-regulation on cytochromes P450 in rat mediated by total alkaloid extract from Corydalis yanhusuo
}

\author{
Jingjing Yan ${ }^{1}$, Xin $\mathrm{He}^{1,2^{*}}$, Shan Feng ${ }^{1}$, Yiran Zhai ${ }^{1}$, Yetao Ma', Sheng Liang ${ }^{1}$ and Chunhuan Jin ${ }^{1}$
}

\begin{abstract}
Background: Yanhusuo (Corydalis yanhusuo W.T. Wang; YHS), is a well-known traditional Chinese herbal medicine, has been used in China for treating pain including chest pain, epigastric pain, and dysmenorrhea. Its alkaloid ingredients including tetrahydropalmatine are reported to inhibit cytochromes P450 (CYPs) activity in vitro. The present study is aimed to assess the potential of total alkaloid extract (TAE) from YHS to effect the activity and mRNA levels of five cytochromes P450 (CYPs) in rat.
\end{abstract}

Methods: Rats were administered TAE from YHS (0, 6, 30, and $150 \mathrm{mg} / \mathrm{kg}$, daily) for 14 days, alanine aminotransferase (ALT) levels in serum were assayed, and hematoxylin and eosin-stained sections of the liver were prepared for light microscopy. The effects of TAE on five CYPs activity and mRNA levels were quantitated by cocktail probe drugs using a rapid chromatography/tandem mass spectrometry (LC-MS/MS) method and reverse transcription-polymerase chain reaction (RT-PCR), respectively.

Results: In general, serum ALT levels showed no significant changes, and the histopathology appeared largely normal compared with that in the control rats. At 30 and $150 \mathrm{mg} / \mathrm{kg}$ TAE dosages, an increase in liver CYP2E1 and CYP3A1 enzyme activity were observed. Moreover, the mRNA levels of CYP2E1 and CYP3A1 in the rat liver, lung, and intestine were significantly up-regulated with TAE from 6 and $30 \mathrm{mg} / \mathrm{kg}$, respectively. Furthermore, treatment with TAE (150 mg/kg) enhanced the activities and the mRNA levels of CYP1A2 and CYP2C11 in rats. However, the activity or mRNA level of CYP2D1 remained unchanged.

Conclusions: These results suggest that TAE-induced CYPs activity in the rat liver results from the elevated mRNA levels of CYPs. Co-administration of prescriptions containing YHS should consider a potential herb (drug)-drug interaction mediated by the induction of CYP2E1 and CYP3A1 enzymes.

Keywords: Total alkaloid extract, Cytochromes P450, Histopathology, Enzyme activity, mRNA level, Herb (drug)-drug interaction

\section{Background}

Corydalis yanhusuo W.T. Wang, belonging to the Papaveraceae family, is a well-known traditional Chinese herbal medicine. The dried and pulverized tubers of C. yanhusuo are called Yanhusuo (YHS). It is among the 50 fundamental herbs in Chinese herbology and has been used traditionally for its sedative, neuroleptic, and analgesic properties [1]. Alkaloids are the main active

\footnotetext{
* Correspondence: hexintn@163.com

'School of Chinese Materia Medica, Tianjin University of Traditional Chinese Medicine, 312 Anshanxi Road, Tianjin 300193, Nankai District, China

${ }^{2}$ Tianjin State Key Laboratory of Modern Chinese Medicine, 312 Anshanxi Road, Tianjin 300193, Nankai District, China
}

constituents isolated from YHS [2], and studies have recently shown that these have extensive pharmacological activities including antitumor [3], antinociceptive [4], antihypertensive [5], and antimyocardial ischemia [6]. levo-Tetrahydropalmatine $(l$-THP) is the main active ingredient of YHS [7], and purified or synthetic $l$-THP is approved for use and available as Rotundine or Rotundin in China [8]. Recently, $l$-THP has been reported to show toxic effects such as depression of neurological, respiratory, and cardiac function in pediatric poisonings, as well as acute or chronic hepatitis after regular use in adults $[9,10]$. 
The effects of YHS on drug-metabolizing enzymes such as cytochromes P450 (CYPs), which are important in controlling xenobiotic metabolism, have occasionally been reported. CYPs is a group of hemoproteins that are important for oxidative metabolism (phase I) of clinically used drugs and other xenobiotics [11]. Co-administration of drugs that are metabolized by CYPs as well as those that induce or inhibit CYPs can cause drug-drug interactions, and these interactions may lead to severe effects [12]. A few alkaloid constituents of YHS have been reported to induce or inhibit CYPs. For example, tetrahydropalmatine (THP) inhibited recombinant human CYP2D6 $\left(\mathrm{IC}_{50}=3.04 \mu \mathrm{M} \pm 0.26 \mu \mathrm{M}\right)$ and recombinant human CYP3A4 $\left(\mathrm{IC}_{50}=41.5 \mu \mathrm{M} \pm 3.8 \mu \mathrm{M}\right)$ activities [13]; THP enantiomers were metabolized mainly by CYP3A4/5 and CYP1A2 in human liver microsomes (HLMs), and $l$-THP significantly inhibited CYP2D6 activity [14]; protopine and allocryptopin induce CYP1A1 expression but have no influence on its enzyme activity in HepG2 cells [15].

However, information about whether total alkaloid extract (TAE) from YHS influences CYPs in vivo, especially after repeated administration, is limited. In the present study, a range of dosages of TAE from YHS $(0,6,30$, and $150 \mathrm{mg} / \mathrm{kg}$ ) were orally administered to male SpragueDawley rats. The effects of TAE on the expression of five drug-processing genes including CYP1A2, CYP2C11, CYP2D1, CYP2E1, and CYP3A1 were investigated. Moreover, CYPs activities and hepatotoxicity were characterized.

\section{Methods}

\section{Plant material}

The dried and pulverized tubers of yanhusuo were purchased from Tianjin Tongrentang pharmacy (Tianjin, China) in October by M. Li (department of pharmacognosy, Tianjin University of TCM, China). The voucher specimen was deposited at the Academy of Traditional Chinese Medicine of Tianjin University of TCM (No. 2012).

\section{Chemicals and reagents}

Phenacetin (PHE), paracetamol (PAR), tolbutamide (TOL), 4-hydroxytolbutamide (OHTOL), dextromethorphan (DEXM), dextrorphan (DEXP), midazolam (MDZ), 1hydroxymidazolam (OHMDZ), chlorzoxazone (CHL), 6-hydroxychlorzoxazone $(\mathrm{OHCHL}), \beta$-nicotinamide adenine dinucleotide phosphate (NADPH) were purchased from Sigma Chemical Co. (St. Louis, MO, USA); carbamazepine (internal standard), phenobarbital (PB) were obtained from the National Institute for the Control of Pharmaceutical and Biological Products (Beijing, China). Methanol and acetonitrile were high performance liquid chromatography-grate from Concord Corporation (Tianjin, China). Ultra-pure water was obtained from a Milli-Q Pluswater purification system (Millipore, Bedford, MA, USA). All other regents were of analytical grade.

\section{Animals}

Male Sprague-Dawley rats (age, 5-7 weeks; weight, 210230 g) were purchased from the Laboratory Animal Science and Technology of Tianjin Shanchuanhong Co., Ltd (Tianjin, China, Certificate No. SCXK-2013-0004). All rats were kept under a standard 12-h dark/light cycle with water and food provided ad libitum. All procedures involving animals were conducted in conformity with the Animal Research: Reporting In Vivo Experiments (ARRIVE) guidelines, and were approved by the Academy of Military Medical Science Institutional Animal Care and Use Committee (Certificate No. SCXK620076004).

\section{Sample preparation and analysis}

The dried and pulverized tubers of yanhusuo $(2 \mathrm{Kg})$ were refluxed with $70 \%$ alcohol for three times. The pooled extract was concentrated under vacuum drying at $50^{\circ} \mathrm{C}$. The dry powder was then dissolved in $200 \mathrm{~mL}$ water. The extracted solution was purified using 732 strong acid cation exchange resin, and the following elution program was used: six times water, and six times 70\% ethanol:water containing 5\% ammonia. A solution of $70 \%$ ethanol:water containing 5\% ammonia was obtained, and the solvent was evaporated under reduced pressure. Preliminary analysis of the extracts was performed using an Agilent 1200 series high performance liquid chromatography (HPLC) instrument (Agilent Technologies, USA). Chromatographic separation was performed using an Agilent Zorbax $\mathrm{HC}-\mathrm{C}_{18}(4.6 \mathrm{~mm} \times$ $250 \mathrm{~mm} \times 5 \mu \mathrm{m})$ column (Agilent, USA). The mobile phase were (A) $0.5 \%$ phosphate buffer ( $\mathrm{pH}$ 5.0) and (B) methanol and the elution system was as follows: 0 - $25 \mathrm{~min}$, from $85 \%$ A to $70 \% \mathrm{~A} ; 25-75 \mathrm{~min}$, from $70 \%$ A to $65 \% \mathrm{~A} ; 75-103 \mathrm{~min}$, from $65 \%$ A to $25 \% \mathrm{~A} ; 103$ $105 \mathrm{~min}$, from $25 \%$ A to $20 \% \mathrm{~A}$; 105 - $115 \mathrm{~min}$, from $20 \%$ A to $85 \% \mathrm{~A} ; 115-125 \mathrm{~min}, 85 \% \mathrm{~A}$. The flow rate was $1.0 \mathrm{~mL} / \mathrm{min}$, and the UV wavelength was $280 \mathrm{~nm}$. The major alkaloids in YHS extract were quantified, and HPLC (Figure 1) showed that the contents (w/w) of protopine, allocryptopin, dehydrocorydaline, tetrahydropalmatine, corydaline, tetrahydroberberine, and glaucine were $2.52 \%, 1.67 \%, 0.34 \%, 3.58 \%, 3.0 \%, 0.22 \%$, and $0.66 \%$, respectively. Figure 2 presents the structures of the alkaloid components. The total alkaloid content $(>45 \%$ in the extract) was determined by UV spectroscopy.

\section{Experimental procedure}

Rats were randomly divided into 5 groups (total 50 rats, $\mathrm{n}=10$ ): three TAE-treated groups, the control group, and the positive control group, respectively. In 14 consecutive days, TAE-treated groups were given TAE orally at doses of $6,30,150 \mathrm{mg} / \mathrm{kg}$ once daily, the positive control group was intraperitoneal injection with phenobarbital (80 mg/kg) once daily [16], whereas the control 


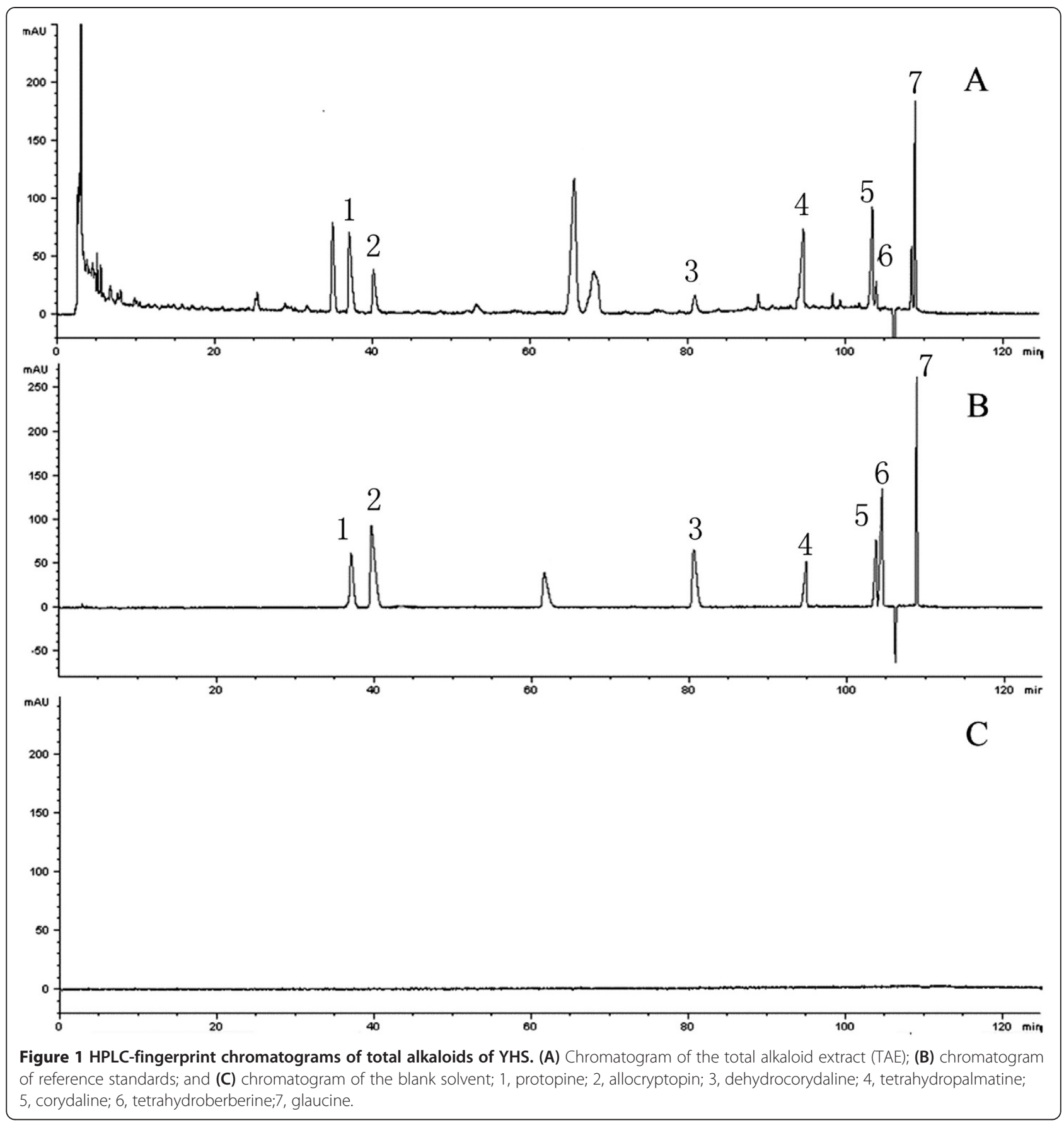

group was orally with equivalent $0.5 \%$ sodium carboxymethylcellulose solution $(5 \mathrm{~mL} / \mathrm{kg})$ once daily. After two weeks, the rats were quickly anaesthetized with urethane $(140 \mathrm{mg} / \mathrm{kg}, 20 \% \mathrm{w} / \mathrm{v}$ solution in $0.9 \% \mathrm{NaCl})$ and then sacrificed by exsanguination of aorta abdominalis. The blood samples were centrifuged at $10000 \mathrm{~g}$ for $5 \mathrm{~min}$ at $4^{\circ} \mathrm{C}$. Serum was collected immediately after each spin and stored at $-80^{\circ} \mathrm{C}$ until the time of assay. Livers, kidneys, lungs and intestines were removed immediately and rinsed with physiological saline. Liver was cut into small pieces to get the liver tissue. Renal cortex was removed and minced in slices to get the kidneys tissue. Lung was cut into samll pieces to get the lung tissue. To get the intestinal mucosa, pieces of intestine were placed on an ice-cold glass plate, and the intestinal mucosa gently squeezed out. All the tissues were stored at $-80^{\circ} \mathrm{C}$ for further analysis (the TAE dosage of $30 \mathrm{mg} / \mathrm{kg}$ was calculated to equivalent to the clinical dosage). 


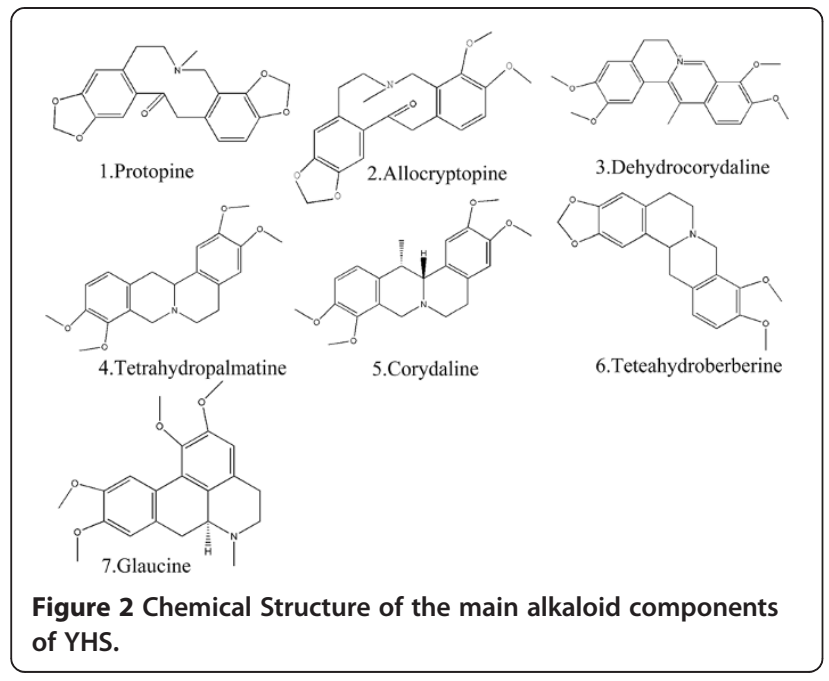

\section{Histopathology and blood biochemistry}

Following the 14-day treatment, livers were removed from the rats, fixed in $10 \%$ neural buffered formalin for $48 \mathrm{~h}$, processed, embedded in paraffin, sectioned at $4 \mu \mathrm{m}$, and stained with hematoxylin and eosin for histological evaluation. Incidence of hepatic lesions was determined by histologically examining the same liver section from each animal [12]. Serum alanine aminotransferase (ALT) levels were determined using a commercial kit, GPT-UV test Nanjing jiancheng (Nanjing jiancheng Bioengineering Institute). The potential hepatotoxicity to animals treated with different TAE dosages was determined.

\section{Microsomal CYPs activity detection}

Microsomes were isolated from the rats livers (approximately $2 \mathrm{~g}$ ) as described [17]. A rapid chromatography/ tandem mass spectrometry (LC-MS/MS) method was applied for determination of the activity of five CYPs in the rat liver [18]. The HPLC system consisted of an LC20 AD pump, a DGU-20 A3 degasser, an SIL-20 AC autosampler and a CTO-20A column oven (Shimadzu, Japan). The separation was performed on an Agilent ZORBAX XDB-C18 column $(50 \mathrm{~mm} \times 2.1 \mathrm{~mm} \times 3.5 \mu \mathrm{m}$, Agilent). The flow rate was $0.45 \mathrm{~mL} / \mathrm{min}$ and consisted of water with $0.1 \%$ formic acid (A) and methonal with $0.1 \%$ formic acid (B) using a gradient elution $(0.0$ $0.5 \mathrm{~min}, 98 \% \mathrm{~A} ; 0.5$ - $1.0 \mathrm{~min}$, from $98 \%$ A to $2 \%$ A; 1.0 $2.5 \mathrm{~min}, 2 \% \mathrm{~A} ; 2.5-2.51 \mathrm{~min}$, from $2 \% \mathrm{~A}$ to $98 \% \mathrm{~A}$; $2.51-4.0 \mathrm{~min}, 98 \% \mathrm{~A})$ were used for analysis. An API 4000 Qtrap mass spectrometer (Applied Biosystems, Foster City, CA, USA) equipped with electrospray ion (ESI) source was used for mass analysis and detection. Following optimization of the setting parameters, the ESI source was operated in both poitive mode for (PAR, DEXP, OHMDZ, OHTOL, and carbamazepine) and negative mode for $(\mathrm{OHCHL})$ with the curtain, nebulizer and turbo-gas (all nitrogen) set at 15, 60 and 55 psi, respectively. The source temperature was $550^{\circ} \mathrm{C}$ and the ion spray needle voltage was $5000 \mathrm{~V}$ in poitive mode and $-4200 \mathrm{~V}$ in negative mode. PHE (CYP1A2), TOL (CYP2C11), DEXM (CYP2D1), CHL (CYP2E1), and MDZ (CYP3A1) were selected as the CYPs isoform probe substrates for the current study. The multiple reaction monitoring (MRM) mode was chosen for quantification of the metabolites of the probe substrates (Table 1). The recovery (extraction efficiency) of PAR, OHTOL, DEXP, OHCHL, and OHMDZ from HLMs were determined at three different concentrations of quality control samples ( they were $0.1,0.5$, and $2.5 \mu \mathrm{M})$. The internal standard was carbamazepine $(75 \mathrm{ng} / \mathrm{ml})$. The extraction recoveries of PAR, OHTOL, DEXP, OHCHL and OHMDZ were $86.3 \pm 2.0 \%$, $92.1 \pm 1.6 \%, \quad 87.2 \pm 1.3 \%, \quad 93.3 \pm 2.0 \%$, and $90.8 \pm 1.9 \%$, respectively.

Incubation mixtures $(200 \mu \mathrm{L})$ containing $0.1 \mathrm{M}$ potassium phosphate buffer ( $\mathrm{pH} 7.4), 0.25 \mathrm{mg} / \mathrm{mL}$ rat microsomal protein, and 10/100/2.5/20/5 $\mu \mathrm{M}$ PHE/TOL/ $\mathrm{DEXM} / \mathrm{CHL} / \mathrm{MDZ}$ were preincubated for $5 \mathrm{~min}$ at $37^{\circ} \mathrm{C}$ in a water bath with gentle shaking. The reaction was initiated by addition of $1 \mathrm{mM} \mathrm{NADPH}$ and terminated with $400 \mu \mathrm{L}$ chilled methanol (contained the internal standard of carbamazepine, $75 \mathrm{ng} / \mathrm{ml}$ ) after $20 \mathrm{~min}$ incubation. After shaking ( $2 \mathrm{~min}$ ) and centrifugation (5000 g, $10 \mathrm{~min}$ ), the organic phase was separated and dried. The residues were dissolved in $200 \mu \mathrm{L}$ of methanol and water $(50: 50, \mathrm{v} / \mathrm{v})$ and centrifuged at $10000 \mathrm{~g}$ for $5 \mathrm{~min}$. A $10 \mu \mathrm{L}$ aliquot of supernatant was injected for determination of the metabolites of five CYPs probe substrates (PAR/ OHTOL/DEXP/OHCHL/ OHMDZ) by LC-MS/MS.

\section{RT-PCR}

Total RNA were extracted from the samples of liver (approximately $50 \mathrm{mg}$ ), kidney (approximately $50 \mathrm{mg}$ ), lung (approximately $50 \mathrm{mg}$ ) and intestine (approximately $50 \mathrm{mg}$ ) were extracted using Trizol reagent (Applied Biosystems, Foster City, CA, USA) according to the protocol provided by the manufacturer. The concentration of RNA was determined by spectrophotometry at $260 \mathrm{~nm}$. RNA samples $(2 \mu \mathrm{g})$ were reverse transcribed using the High Capacity cDNA Reverse Transcription Kit (Applied Biosystems, USA) to obtain cDNA according to the manufacture's recommendations. Quantification of mRNA was performed on the Applied Biosystem 7500 Real-Time PCR System (Foster, CA, USA) using SYBR Select Master Mix (Applied Biosystems, USA) according to the manufacture's recommendations. PCR reactions contains an initial denaturating cycle at $95^{\circ} \mathrm{C}$ for $10 \mathrm{~min}$, followed by 40 amplification cycles: $95^{\circ} \mathrm{C}$ for $15 \mathrm{~s}$ and $60^{\circ} \mathrm{C}$ for $1 \mathrm{~min}$. The primer pairs for five CYPs and $\beta$-actin genes and predicted size of PCR products are shown in Table 2. 
Table 1 MRM transitions and collosion energies for the detection of CYPs probe substrate metabolites

\begin{tabular}{llllll}
\hline Substrate metabolite & Molecular mass (MW) & Precursor $(\mathbf{m} / \mathbf{z})$ & Product $(\mathbf{m} / \mathbf{z})$ & Polarity & Collision energy (eV) \\
\hline Paracetamol (PAR) & 151 & 152 & 110 & $\mathrm{ESI}^{+}$ & 23 \\
Dextrorphan (DEXP) & 257 & 258 & 199 & $\mathrm{ESI}^{+}$ & 38 \\
1-Hydroxymidazolam (OHMDZ) & 341 & 342 & 203 & $\mathrm{ESI}^{+}$ & 40 \\
4-Hydroxytolbutamide (OHTOL) & 286 & 287 & 171 & $\mathrm{ESI}^{+}$ & 59 \\
6-hydroxychlorzoxazone (OHCHL) & 185 & 184 & 120 & $\mathrm{ESl}^{-}$ & -26 \\
Kamaxiping (internal standard) & 236 & 237. & 194 & $\mathrm{ESI}^{+}$ & 40 \\
\hline
\end{tabular}

\section{Statistical analysis}

Values are expressed as mean \pm SD. The enzyme activity was calculated as follows: enzyme activity $=\mathrm{C}_{\text {metabolite }} \times$ $\mathrm{L}_{\text {incubation }} / \mathrm{T}_{\text {incubation }} /\left(\mathrm{C}_{\mathrm{HLMs}} \times \mathrm{L}_{\text {incubtiaon }}\right)$, in which $\mathrm{C}_{\text {me- }}$ tabolites represents the concentration of metabolites of CYPs probe substrates, $\mathrm{L}_{\text {incubation }}$ represents the volume of incubation system, $\mathrm{T}_{\text {incubation }}$ represents the incubation time, and $\mathrm{C}_{\mathrm{HLMs}}$ represents the concentration of HLMs. Values were expressed in units of $\mathrm{pmol} \cdot \mathrm{min}^{-1} \cdot \mathrm{mg}^{-1}$. Independent-sample t-test was used to analyze the differences between the enzyme activities, gene expression values with control values by SPSS 13.0. Differences were considered significant at $P<0.05$.

\section{Results}

Liver function of TAE-treated rats

No significant change was observed in serum ALT levels in the TAE-treated rats (data not shown). Figure 3

Table 2 Sequences of the primers in reverse transcription and quantitative real-time PCR

\begin{tabular}{|c|c|c|}
\hline Gene name & Sequence & Product size (bp) \\
\hline \multicolumn{3}{|l|}{$\beta$-actin } \\
\hline Forward & ACCCCAAAGCCAACAGAGAG & 102 \\
\hline Reverse & AGGCATACAGGGACAGCACA & \\
\hline \multicolumn{3}{|l|}{ CYP1A2 } \\
\hline Forward & CATAGCCTCAGACCCCACAT & 165 \\
\hline Reverse & ATGGCTCCGATGACATTAGC & \\
\hline \multicolumn{3}{|l|}{ CYP2C11 } \\
\hline Forward & AGGGCCTTGGAGTCATITाT & 163 \\
\hline Reverse & GCACCTTGCTCTTCCTCAG & \\
\hline \multicolumn{3}{|l|}{ CYP2D1 } \\
\hline Forward & GCTGACAAGGTCTTCCAAGG & 188 \\
\hline Reverse & ACCACCATGCGTAGGTTCTC & \\
\hline \multicolumn{3}{|l|}{ CYYP2E1 } \\
\hline Forward & ATGTCATCCCCAAGGGTACA & 184 \\
\hline Reverse & AGGCCTTCTCCAACACACAC & \\
\hline \multicolumn{3}{|l|}{ CYP3A1 } \\
\hline Forward & TATGGGGAAAGCCATCTCTG & 164 \\
\hline Reverse & CAGGTTTGCCTITCTCTTGC & \\
\hline
\end{tabular}

presents the histopathology microphotos. On histopathological examination, the control rats showed clear dividing lines of hepatic lobules. Their structure was complete, and the hepatic cord was orderly and was arranged radially around a central vein (Figure 3A). Liver portions from the TAE-treated rats (Figure 3B-D) did not show morphological alterations relative to the control rats (Figure 3A).

\section{Influence of TAE on CYPs activity in the rat liver}

After TAE treatment, CYPs activities in the rat liver were quantified using a cocktail of probe drugs and LCMS/MS. TAE significantly increased the enzyme activities of CYP2E1 and CYP3A1. In the treated rats, the three TAE dosages $(6,30$, and $150 \mathrm{mg} / \mathrm{kg}$, daily) significantly increased the enzyme activity of CYP2E1 by $20 \%$, $68.2 \%$, and $146.1 \%$, respectively, and the three TAE dosages

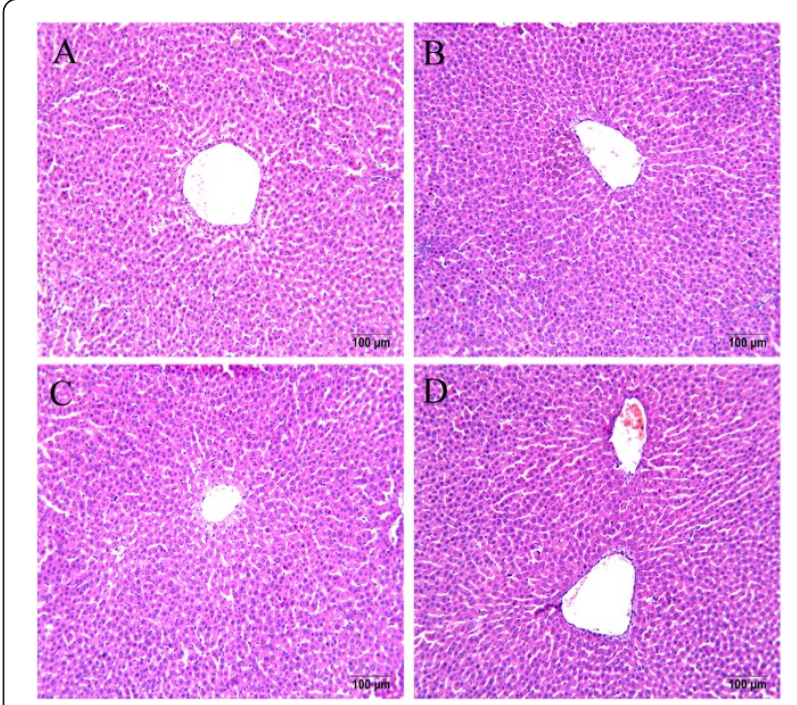

Figure 3 Histopathological examination of liver sections from rats treated with TAE from YHS. Liver sections of male Sprague-Dawley rats treated with various dosages of TAE showed largely normal appearances. For each dosage group, four sections were made, and the microphotos show representative foci in the control rats (A), $6 \mathrm{mg} / \mathrm{kg}$ (B), $30 \mathrm{mg} / \mathrm{kg}$ (C), and $150 \mathrm{mg} / \mathrm{kg}$ (D) TAE-treated rats. Tissues were fixed in formalin and stained with hematoxylin and eosin. Magnification: $200 \times$. 
increased the levels of CYP3A1 by $27.84 \%, 40.3 \%$ and $51.9 \%$, respectively, compared with those in the control rats. The highest TAE dosage $(150 \mathrm{mg} / \mathrm{kg}$, daily) increased the enzyme activity of CYP1A2 by $44.9 \%$ and the enzyme activity of CYP2C11 by $35.4 \%$. The three TAE-treated groups were not significantly different from the control groups in terms of CYP2D1 expression $(P>0.05$; Table 3$)$.

\section{Regulation of CYP2E1 and CYP3A1 MRNA by TAE in the rat liver, kidney, lung, and intestine}

Figure 4 presents the effects of TAE on the mRNA levels of CYP2E1 and CYP3A1. TAE at 6 and $30 \mathrm{mg} / \mathrm{kg}$ markedly increased the mRNA levels of CYP2E1 and CYP3A1, respectively, whereas TAE at $150 \mathrm{mg} / \mathrm{kg}$ increased the mRNA levels of CYP3A1 in the rat kidney. The mRNA levels of CYP2E1 in the rat kidney remained unchanged. At the highest dosage, the mRNA levels of CYP2E1 increased 2.0-, 2.9-, and 4.6-fold in the rat liver, lung, and intestine, respectively, when normalized to the mRNA level of $\beta$-actin. The gene expression levels of CYP2E1 and CYP3A1 increased dosage dependently.

\section{Regulation of CYP1A2, CYP2C11, and CYP2D1 mRNA by TAE in the rat liver, kidney, lung, and intestine} Changes in the mRNA levels of CYP1A2, CYP2C11, and CYP2D1 were evaluated by real-time PCR. As shown in Figure 5, TAE increased the mRNA levels of CYP1A2 at the highest dosage and showed 2.9-, 2.4-, and 2.2-fold increase in the CYP1A2/ $\beta$-actin mRNA levels in the rat liver, lung, and intestine. No effect of the two lower dosages of TAE was observed on the gene expression levels of CYP2C11 $(P>0.05)$, and only up-regulation of the gene expression levels of CYP2C11 at the highest dosage was significant in the rat liver, which showed 2.3-fold increase in the CYP1A2/ $\beta$-actin mRNA levels. We were unable to detect changes in the mRNA levels of CYP2C11 in the rat kidney, lung, and intestines because of the low gene expression levels of CYP2C11 in these organs. The mRNA levels of CYP2D1 did not change significantly among the three TAE dosages.

\section{Discussion}

\section{CYP2E1 induction associated with TAE toxicity}

In traditional Chinese herbal medicine, YHS is generally used to dispel stasis and move $q i$, reinforce vital energy, and relieve painful conditions such as headache, chest pain, and abdominal pain [19]. The main active ingredient of YHS is alkaloids; therefore, it is necessary to elucidate the possible interactions of alkaloids with the metabolism of drugs and other xenobiotics.

To date, some compounds in YHS have been found to exert the inhibitory or inductive effects on CYPs [20,21], but little is known about the effect of TAE from YHS on CYPs expression. The present study was designed to investigate whether TAE from YHS affects the expression of CYP1A2, CYP2C11, CYP2D1, CYP2E1, and CYP3A1 in rats.

CYP2E1 catalyzes the biotransformation of almost $2 \%$ of all clinically used drugs in humans [22]. Rat CYP2E1 is a homolog of human CYP2E1 [23] and is expressed in many tissues including the liver [11]. CYP2E1 is a classical ethanol-inducible CYPs and has been extensively studied for long because of it catalyzes the bioactivation of several procarcinogens and protoxins including $\mathrm{N}$-nitrosodimethylamine, benzene, and carbon tetrachloride [24]. CYP2E1-mediated metabolism generates reactive oxygen species, such as oxygen and hydroxyl radicals, when these exceed the cellular detoxification systems, it results in oxidative stress with its various pathologic consequences [11]. Oxygen radicals play a key role in liver injury because of their interaction with cellular proteins or DNA $[11,25]$. CYP2E1 overexpression generated oxidative stress in a human hepatoma cell line and induced cytotoxicity to the cells [26], and CYP2E1 induction could alter immune system responses, leading to increased susceptibility to viral infection [27]. Furan is metabolized by CYP2E1 to a toxic metabolite, cis-2-butene-1,4-dial, that may interact with proteins to cause cytotoxicity or react with nucleosides to form substituted deoxyguanosine adducts [28].

Cases of human poisoning have occurred because of unregulated use of proprietary biopharmaceuticals containing purified THP. Several case reports associate the development of acute or chronic hepatitis with the

Table 3 Effects of TAE from YHS on CYPs activity in the rat liver

\begin{tabular}{|c|c|c|c|c|c|c|}
\hline \multirow[b]{2}{*}{ Group } & \multirow{2}{*}{$\begin{array}{l}\text { Dosage } \\
\left(\mathrm{mg} \cdot \mathrm{kg}^{-1}\right)\end{array}$} & \multicolumn{5}{|c|}{ The activities of CYPs $\left(\mathrm{pmol} \cdot \mathrm{min}^{-1} \cdot \mathrm{mg}^{-1}\right)$} \\
\hline & & $1 \mathrm{A2}$ & $2 C 11$ & 2D1 & $2 \mathrm{E} 1$ & $3 A 1$ \\
\hline Control & & $107.67 \pm 2.36$ & $116.00 \pm 3.77$ & $125.78 \pm 9.05$ & $299.33 \pm 23.57$ & $175.56 \pm 3.35$ \\
\hline Positive control & & $152.67 \pm 2.82^{* *}$ & $172.67 \pm 2.83^{*}$ & $135.40 \pm 1.50$ & $930.00 \pm 21.40^{* *}$ & $351.00 \pm 0.47^{* *}$ \\
\hline \multirow[t]{3}{*}{ TAE } & 6 & $97.78 \pm 2.69$ & $107.33 \pm 0.67$ & $120.67 \pm 4.16$ & $358.89 \pm 23.65^{*}$ & $224.44 \pm 1.92^{*}$ \\
\hline & 30 & $107.56 \pm 9.46$ & $112.22 \pm 6.68$ & $121.56 \pm 6.74$ & $503.33 \pm 21.86^{* *}$ & $246.33 \pm 2.36^{*}$ \\
\hline & 150 & $155 \pm 9.90^{* *}$ & $157.11 \pm 3.67^{*}$ & $125.78 \pm 3.79$ & $736.67 \pm 14.14^{* *}$ & $266.67 \pm 5.66^{*}$ \\
\hline
\end{tabular}

Data are presented as mean \pm SD of three rats. ${ }^{*} P<0.05,{ }^{* *} P<0.01$, values significantly different from the control rats. 


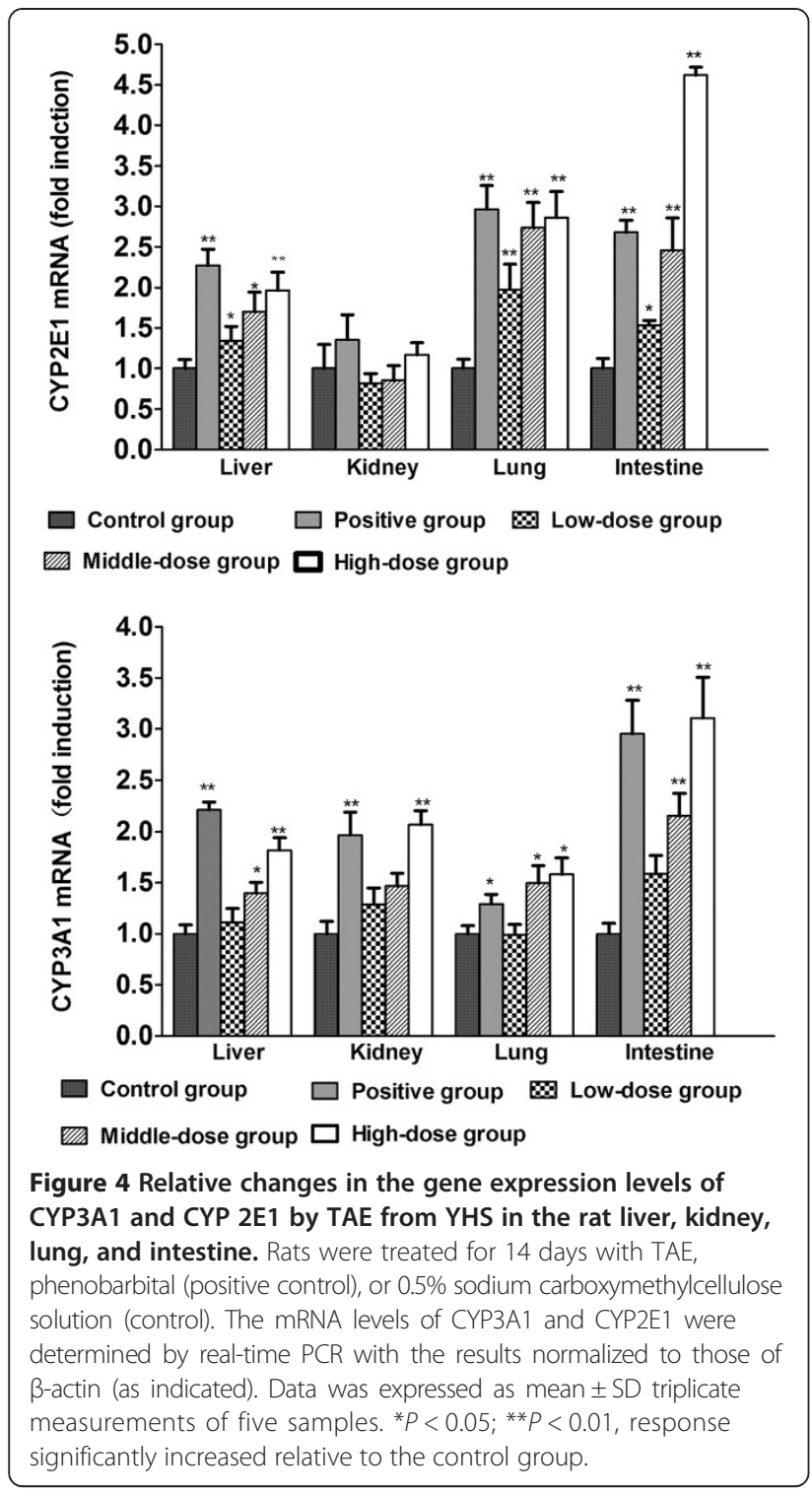

chronic ingestion of a Chinese herbal medication "Jin $\mathrm{Bu}$ Huan Anodyne Tablets" [29,30], which contains purified, concentrated $l$-THP, and the plant alkaloid responsible for its toxicity $[9,30]$. In the present study, after the treatment of rats for 14 days with TAE, both the enzyme activity and mRNA level of CYP2E1 were significantly increased at all three TAE dosages. The liver injury caused by YHS may thus have resulted from the induction of the drug metabolic enzyme CYP2E1 by longterm administration of YHS. Drug-drug interactions are of concern when low-dosage TAE from YHS as well as substrates of CYP2E1 are administered.

\section{Induction ability of TAE on CYP3A1 in rats}

The CYP3A subfamily is the most important hepatic metabolic enzyme in the metabolism of $40 \%$ to $60 \%$ of
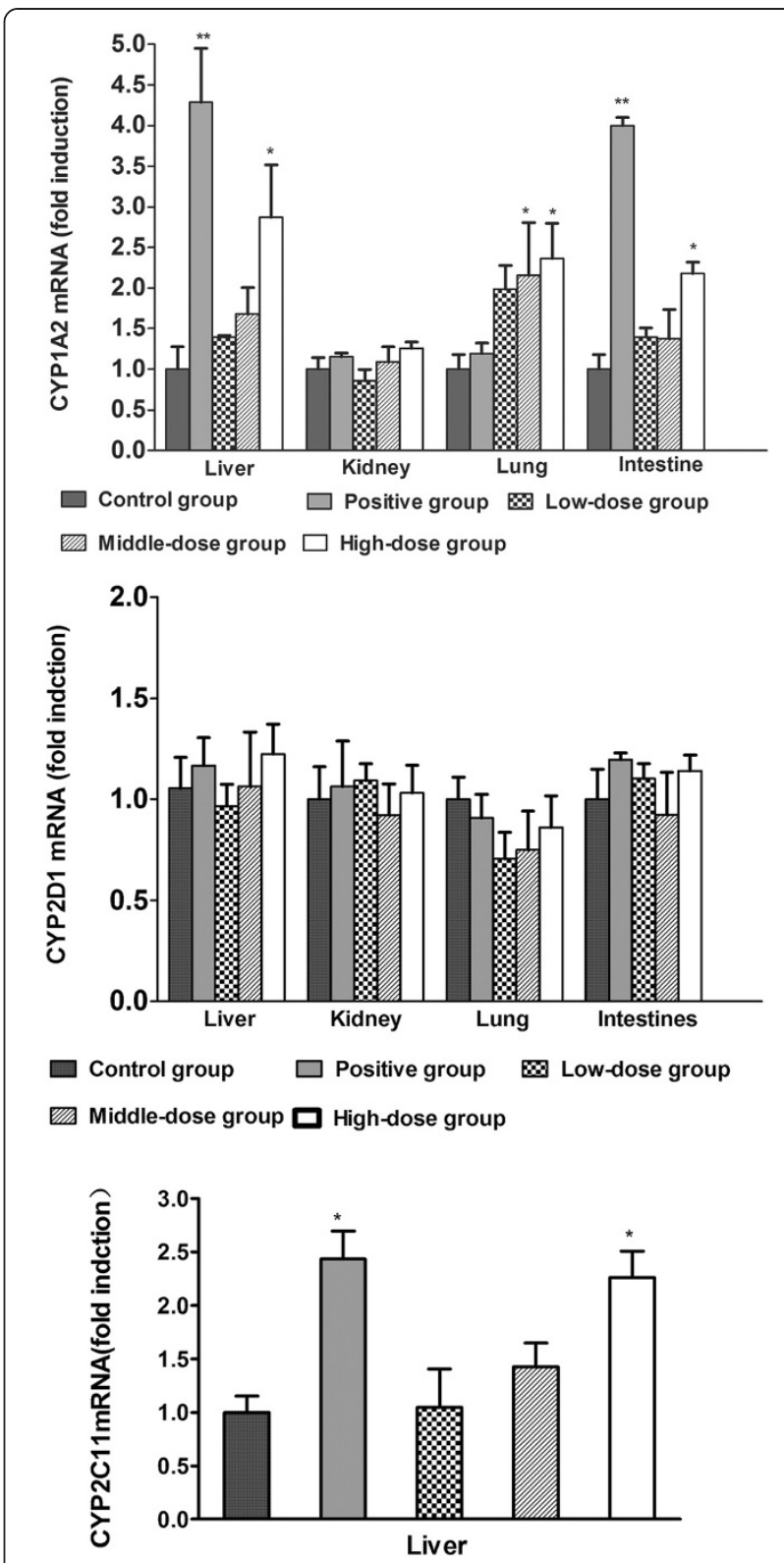

$\square$ Control group $\square$ Positive group $\otimes$ Low-dose group

Middle-dose group $\square$ High-dose group

Figure 5 Relative changes in the gene expression levels of CYP1A2, CYP2D1 and CYP2C11 by TAE from YHS in the rat liver, kidney, lung, and intestine. Rats were treated for 14 days with TAE, phenobarbital (positive control), or $0.5 \%$ sodium carboxymethylcellulose solution (control). The mRNA levels of CYP1A2, CYP2D1, and CYP2C11 were determined by real-time PCR with the results normalized to those of $\beta$-actin (as indicated). Data was expressed as mean \pm SD triplicate measurements of five samples. ${ }^{*} P<0.05$; ${ }^{*} P<0.01$, response significantly increased relative to the control group.

all drugs [31]. CYP3A4 is the most abundant CYP in the human liver, where it accounts for $30 \%$ of CYPs [22], and rat CYP3A1 is a homolog of human CYP3A4 [32]. CYP3A1 can catalyse the $6 \beta$-hydroxylation of testosterone 
[33] and the metabolism of a large variety of clinical medications, including many pediatric drugs [34], cyclosporin A [35]. Induction of CYP3A4 expression accelerated the clearance of several clinically important drugs including midazolam, amitriptyline, cyclosporin, and oral contraceptives [36]. Ginkgolide A and ginkgolide B induced the protein expression and enzyme activity of CYP3A in the primary cultures of human hepatocytes at $30 \mu \mathrm{mol} / \mathrm{L}$ [37]. In the present study, CYP3A1 was significantly induced in the rat liver, lung, and intestine at $30 \mathrm{mg} / \mathrm{kg}$ (equivalent to the clinical dosage), suggesting that TAE has the potential to produce CYP3A-mediated drug-drug interactions. Consumption of YHS or YHS-containing products with the substrates of CYP3A should be taken more attention because of the possibility of drug-drug interactions.

\section{The influence of TAE on other CYPs}

After the treatment of rats for 14 days with different dosages of TAE, significant increases were observed in the mRNA expression and enzyme activities of CYP1A2 and CYP2C11 at $150 \mathrm{mg} / \mathrm{kg}$ TAE, but the mRNA levels and enzyme activities of CYP2D1 did not change significantly among the three TAE dosages. In the human liver, CYP1A2, CYP2C and CYP2D6 are involved in the metabolism of $4 \%, 16 \%$, and $30 \%$, respectively, of drugs on the market [11]. CYP1A2 is regulated primarily by the aromatic hydrocarbon receptor (AhR), and CYP1A2 is induced by AhR-mediated transactivation following ligand binding and nuclear translocation [38]. AhR activation and the significant induction of the enzyme activity of CYP1A can accelerate the biotransformation of different procarcinogens and promutagens to carcinogens and mutagens that bind covalently to important functional macromolecules such as DNA, resulting in the carcinogenic transformation of cells [12]. However, in the present study, only rats treated with high-dosage TAE showed an increase in the mRNA levels and enzyme activity of CYP1A2, indicating that TAE has low potential to produce CYP1A-mediated drug-drug interactions. Human CYP2C9 is the major CYP2C form, accounting for $60 \%$ of total human CYP2C [11]. Rat CYP2C11 is considered the counterpart of human CYP2C9 and metabolizes many drugs including S-warfarin and widely used nonsteroidal anti-inflammatory drugs such as diclofenac [39]. CYP2D1 is the rat orthologue of human CYP2D6, and CYP2D6 has been the most studied human genetic polymorphism in drug metabolism [11]. In vivo clearance of CYP2D6 substrates in poor metabolizers is generally much lower than in extensive metabolizers, leding to higher plasma concentrations and the potential for clinical toxicities with therapeutic doses [40]. Our results suggest that TAE can induce the mRNA levels and enzyme activity of CYP2C11 in the rat liver only at the higher concentrations tested, suggesting that clinically important CYP2C11-mediated drug-herb interactions are unlikely to be induced by TAE from YHS. And TAE did not affect CYP2D1 mRNA level and activity in three doses, the finding suggests that the use of products containing YHS may be considered safe when co-administration with CYP2D1 substrates.

\section{Conclusions}

TAE from YHS significantly induced the mRNA expression and enzyme activity of CYP2E1 and CYP3A1 in the rat liver, lung, and intestine. Furthermore, enzyme activity correlated well with mRNA expression. The results of the present dose-response study in rats suggest that potential CYP2E1 and CYP3A drug-drug interactions are unlikely at clinical dosages of TAE, but need to be considered when high dosages of TAE or TAE-containing products are coadministered with substrates of CYP1A2 or CYP2C11. Complex herb (drug)-drug interactions may ensue from the co-administration of YHS with other drugs, which is mediated by CYP2E1 and CYP3A1 enzymes.

\section{Abbreviations}

YHS: Yanhusuo; CYPs: Cytochromes P450; TAE: Total alkaloid extract; HLMs: Human liver microsomes; I-THP: levo- Tetrahydropalmatine; PHE: Phenacetin; PAR: Paracetamol; TOL: Tolbutamide; OHTOL: 4-hydroxytolbutamide; DEXM: Dextromethorphan; DEXP: Dextrorphan; CHL: Chlorzoxazone; OHCHL: 6-hydroxychlorzoxazone; MDZ: Midazolam; OHMDZ: 1-Hydroxymidazolam; NADPH: $\beta$-Nicotinamide adenine dinucleotide phosphate; PB: Phenobarbital; i.p: Intraperitoneal; AhR: Aromatic hydrocarbon receptor.

\section{Competing interests}

The authors declare that they have no competing interests.

\section{Authors' contributions}

XH designed the study. JJY, SF, YRZ, YTM, SL and CHJ participated in the sample preparation and animal experiments. XH, JJY and SF were responsible for data analyses and manuscript preparation. JJY drafted the manuscript. All authors read the final manuscript.

\section{Acknowledgements}

This study was supported by National Natural Science Foundation of China [NSFC, No.81373890 and No.81430096]; Research Fund for the Doctoral Program of Higher Education [RFDP, No.20121210110011]; Natural Science Foundation of Tianjin (No.12JCZDJC26100).

Received: 3 March 2014 Accepted: 5 August 2014

Published: 18 August 2014

\section{References}

1. Liu YL, Yan LD, Zhou PL, Wu CF, Gong ZH: Levo-tetrahydropalmatine attenuates oxycodone-induced conditioned place preference in rats. Eur J Pharmacol 2009, 602:321-327.

2. He K, Gao JL, Zhao GS: Advances in studies on chemistry, pharmacology and quality control of Corydalis yanhusuo. Zhong Cao Yao 2007, 38:11-14.

3. Gao JL, He TC, Li YB, Wang YT: A traditional Chinese medicine formulation consisting of Rhizoma Corydalis and Rhizoma Curcumae exertssynergistic anti-tumor activity. Oncol Rep 2009, 22:1077-1083.

4. Choi JG, Kang SY, Kim JM, Roh DH, Yoon SY, Park JB, Lee JH, Kim HW: Antinociceptive effect of Cyperi rhizoma and Corydalis tuber extracts on neuropathic pain in rats. Korean J Physiol Pharmacol 2012, 16:387-392.

5. Chueh FY, Hsieh MT, Chen CF, Lin MT: DL-tetrahydropalmatine-produced hypotension and bradycardia in rats through the inhibition of central nervous dopaminergic mechanisms. Pharmacology 1995, 51:237-244. 
6. Ling H, Wu L, Li L: Corydalis yanhusuo rhizoma extract reduces infarct size and improves heart function during myocardial ischemia/ reperfusion by inhibiting apoptosis in rats. Phytother Res 2006, 20:448-453.

7. Chu H, Jin G, Friedman E, Zhen X: Recent development in studies of tetrahydroprotoberberines: mechanism in antinociception and drug addiction. Cell Mol Neurobiol 2008, 28:491-499.

8. Wang JB, Mantsch JR: L-tetrahydropalamatine: a potential new medication for the treatment of cocaine addiction. Future Med Chem 2012, 4:177-186.

9. Lai CK, Chan AY: Tetrahydropalmatine poisoning: diagnoses of nine adult overdoses based on toxicology screens by HPLC with diode-array detection and gas chromatography-mass spectrometry. Clin Chem 1999, 45:229-236.

10. Li L, Ye M, Bi K, Guo D: Liquid chromatography-tandem mass spectrometry for the identification of L-tetrahydropalmatine metabolites in Penicillium janthinellum and rats. Biomed Chromatogr 2006, 20:95-100.

11. Martignoni M, Groothuis GM, de Kanter R: Species differences between mouse, rat, dog, monkey and human CYP-mediated drug metabolism, inhibition and induction. Expert Opin Drug Metab Toxicol 2006, 2:875-894

12. Guo Y, Pope C, Cheng X, Zhou H, Klaassen CD: Dose-response of berberine on hepatic cytochromes P450 mRNA expression and activities in mice. J Ethnopharmacol 2011, 138:111-118.

13. Zhao $Y$, Hellum BH, Liang A, Nilsen OG: The in vitro inhibition of human CYP1A2, CYP2D6 and CYP3A4 by tetrahydropalmatine, neferine and berberine. Phytother Res 2012, 26:277-283.

14. Sun SY, Wang YQ, Li LP, Wang L, Zeng S, Zhou H, Jiang HD: Stereoselective interaction between tetrahydropalmatine enantiomers and CYP enzymes in human liver microsomes. Chirality 2013, 25:43-47.

15. Vrba J, Vrublova E, Modriansky M, Ulrichova J: Protopine and allocryptopine increase mRNA levels of cytochromes P450 1A in human hepatocytes and HepG2 cells independently of AhR. Toxicol Lett 2011, 203:135-141.

16. Omiecinski CJ, Hassett C, Costa P: Developmental expression and in situ localization of the phenobarbital-inducible rat hepatic mRNAs for cytochromes CYP2B1, CYP2B2, CYP2C6, and CYP3A1. Mol Pharmacol 1990, 38(4):462-470.

17. Stiborová M, Stiborová-Rupertová M, Borek-Dohalská L, Wiessler M, Frei E: Rat microsomes activating the anticancer drug ellipticine to species covalently binding to deoxyguanosine in DNA are a suitable model mimicking ellipticine bioactivation in humans. Chem Res Toxicol 2003, 16:38-47.

18. He F, Bi HC, Xie ZY, Zuo Z, Li JK, Li X, Zhao LZ, Chen X, Huang M: Rapid determination of six metabolites from multiple cytochrome $\mathrm{P} 450$ probe substrates in human liver microsome by liquid chromatography/mass spectrometry: application to high-throughput inhibition screening of terpenoids. Rapid Commun Mass Spectrom 2007, 21:635-643.

19. Chinese Pharmacopoeia Commission: Pharmacopoeia of the People's Republic of China, Part I. Beijing: Chemical Industry Press; 2010:130-131.

20. Zhao M, Li LP, Sun DL, Sun SY, Huang SD, Zeng S, Jiang HD: Stereoselective metabolism of tetrahydropalmatine enantiomers in rat liver microsomes. Chirality 2012, 24:368-373.

21. Paul LD, Springer D, Staack RF, Kraemer T, Maurer HH: Cytochrome P450 isoenzymes involved in rat liver microsomal metabolism of californine and protopine. Eur J Pharmacol 2004, 485:69-79.

22. Zuber R, Anzenbacherová E, Anzenbacher P: Cytochromes P450 and experimental models of drug metabolism. J Cell Mol Med 2002, 6:189-198.

23. Guengerich FP: Comparisons of catalytic selectivity of cytochrome P450 subfamily enzymes from different species. Chem Biol Interact 1997, 106:161-182.

24. Arinc E, Arslan S, Bozcaarmutlu A, Adali O: Effects of diabetes on rabbit kidney and lung CYP2E1 and CYP2B4 expression and drug metabolism and potentiation of carcinogenic activity of $\mathrm{N}$-nitrosodimethylamine in kidney and lung. Food Chem Toxicol 2007, 45:107-118.

25. Gonzalez FJ: The 2006 Bernard B. Brodie Award Lecture. Cyp2e1. Drug Metab Dispos 2007, 35:1-8.

26. Takahashi S, Takahashi T, Mizobuchi S, Matsumi M, Morita K, Miyazaki M, Namba M, Akagi R, Hirakawa M: Increased cytotoxicity of carbon tetrachloride in a human hepatoma cell line overexpressing cytochrome P450 2E1. J Int Med Res 2002, 30:400-405.
27. McKillop IH, Schrum LW: Alcohol and liver cancer. Alcohol 2005, 35:195-203.

28. Neuwirth C, Mosesso P, Pepe G, Fiore M, Malfatti M, Turteltaub K, Dekant W, Mally A: Furan carcinogenicity: DNA binding and genotoxicity of furan in rats in vivo. Mol Nutr Food Res 2012, 56:1363-1374.

29. Picciotto A, Campo N, Brizzolara R, Giusto R, Guido G, Sinelli N, Lapertosa G, Celle G: Chronic hepatitis induced by Jin Bu Huan. J Hepatol 1998, 28:165-167.

30. Horowitz RS, Feldhaus K, Dart RC, Stermitz FR, Beck JJ: The clinical spectrum of Jin Bu Huan toxicity. Arch Intern Med 1996, 156:899-903.

31. Hu HF, Gao ZX, Cheng YY: Inhibition of CYP3A mRNA and protein expression, and enzymatic activity, by enrofloxacin in chickens. J Vet Pharmacol Ther 2010, 33:450-546.

32. Liu A, Yang J, Zhao X, Jiao X, Zhao W, Ma Q, Tang Z, Dai R: Induction of P450 3A1/2 and 2C6 by gemfibrozil in Sprague-Dawley rats. Pharmacol Rep 2011, 63:157-164.

33. Halvorson M, Greenway D, Eberhart D, Fitzgerald K, Parkinson A: Reconstitution of testosterone oxidation by purified rat cytochrome P450p (IIIA1). Arch Biochem Biophys 1990, 277(1):166-180.

34. Xu RA, Xu ZS, Ge RS: Effects of hydroxysafflor yellow $A$ on the activity and mRNA expression of four CYP isozymes in rats. $J$ Ethnopharmacol 2014, 151(3):1141-1146.

35. Debri K, Boobis AR, Davies DS, Edwards RJ: Distribution and induction of CYP3A1 and CYP3A2 in rat liver and extrahepatic tissues. Biochem Pharmaco 1995, 50(12):2047-2056.

36. Qiu F, Wang G, Zhang R, Sun J, Jiang J, Ma Y: Effect of danshen extract on the activity of CYP3A4 in healthy volunteers. Br J Clin Pharmacol 2010, 69:656-662.

37. He N, Cai HB, Xie HG, Collins X, Edeki TI, Strom SC: Induction of cyp3a in primary cultures of human hepatocytes by ginkgolides a and B. Clin Exp Pharmacol Physiol 2007, 34:632-635.

38. Zhou SF, Wang B, Yang LP, Liu JP: Structure, function, regulation and polymorphism and the clinical significance of human cytochrome P450 1A2. Drug Metab Rev 2010, 42:268-354.

39. Večeřa $R$, Zachařová A, Orolin J, Strojil J, Skottová N, Anzenbacher P: Fenofibrate-induced decrease of expression of CYP2C11 and CYP2C6 in rat. Biopharm Drug Dispos 2011, 32:482-487.

40. Bertelsen KM, Venkatakrishnan K, Von Moltke LL, Obach RS, Greenblatt DJ: Apparent mechanism-based inhibition of human CYP2D6 in vitro byparoxetine: comparison with fluoxetine and quinidine. Drug Metab Dispos 2003, 31:289-293.

\section{doi:10.1186/1472-6882-14-306}

Cite this article as: Yan et al:: Up-regulation on cytochromes P450 in rat mediated by total alkaloid extract from Corydalis yanhusuo. BMC Complementary and Alternative Medicine 2014 14:306.

\section{Submit your next manuscript to BioMed Central and take full advantage of:}

- Convenient online submission

- Thorough peer review

- No space constraints or color figure charges

- Immediate publication on acceptance

- Inclusion in PubMed, CAS, Scopus and Google Scholar

- Research which is freely available for redistribution 